\title{
Ozonation as an effective pretreatment for reducing antibiotic resistance selection potency in oxytetracycline production wastewater
}

\author{
Miaomiao Liu ${ }^{\mathrm{a}, \mathrm{b}}$, Yu Zhang ${ }^{\mathrm{c}, \mathrm{d}, *}$, Hong Zhang $^{\mathrm{c}}$, Haifeng Zhang ${ }^{\mathrm{c}}$, \\ Kuixiao Li ${ }^{\mathrm{a}}$, Zhe Tiana, Min Yanga,d \\ aState Key Laboratory of Environmental Aquatic Chemistry, Research Center for Eco-Environmental Sciences, \\ Chinese Academy of Sciences, Beijing 100085, China, emails: Immhit@163.com (M. Liu), kuixiao2008@yahoo.com.cn (K. Li), \\ tianzhescu@163.com (Z.Tian),yangmin@rcees.ac.cn (M. Yang) \\ ${ }^{b}$ Department of Civil and Environmental Engineering, Beijing Jiaotong University, Beijing 10004, China \\ 'Key Laboratory of Drinking Water Science and Technology, Research Center for Eco-Environmental Sciences, \\ Chinese Academy of Sciences, Beijing 100085, China, Tel. +86-10-62919883; Fax: +86-10-62923541; \\ emails: zhangyu@rcees.ac.cn (Y. Zhang), zhanghong20061014@163.com (H. Zhang), haifeng.hf@gmail.com (H. Zhang) \\ 'University of Chinese Academy of Sciences, Beijing 100049, China
}

Received 24 October 2016; Accepted 20 February 2017

\begin{abstract}
A B S T R A C T
High concentrations of antibiotics in wastewater can promote antibiotic resistance during biological wastewater treatment. In this work, ozonation was evaluated regarding its removal efficiency of antibiotic, antimicrobial activity, and antibiotic resistance selection potency from oxytetracycline (OTC) production wastewater. Doses of 0.4 and $1.2 \mathrm{mg} \mathrm{O}$ per $\mathrm{mg}$ of initial OTC permitted $100 \%$ and $92 \%$ OTC removal from OTC solution (OTC, $10 \mathrm{mg} / \mathrm{L}$ ) and OTC production waste mother liquor (OTC, $702 \mathrm{mg} / \mathrm{L})$, respectively. With the removal of OTC, the OTC solution lost its antibacterial activity against Streptococcus aureus. The antibiotic resistance selection potency of OTC before and after ozonation was also evaluated. When activated sludge was exposed to OTC $(10 \mathrm{mg} / \mathrm{L})$ solution for $18 \mathrm{~d}$, the OTC-resistant bacteria ratio increased from $2.0 \%$ to $28.2 \%$, and the relative abundances of tetracycline resistance genes $(\operatorname{tet}(\mathrm{A})$, tet $(\mathrm{X}))$ and class 1 integron increased from $1.01 \%$ to $5.36 \%$ $(p<0.05)$. However, no significant change of OTC resistance was observed in activated sludge exposed to ozonated OTC solution, implying that the antibiotic resistance selection potency of OTC was alleviated by ozonation. This study demonstrated that ozonation can reduce antibiotic resistance selection potency from OTC production wastewater with a reasonable ozone dose.
\end{abstract}

Keywords: Ozonation; Oxytetracycline production wastewater; Antibacterial potency; Antibiotic resistance; Removal of antibiotic resistance selection potency

\footnotetext{
* Corresponding author.
} 